\title{
Physical Incompatibility between Parenteral Cloxacillin and Vancomycin
}

\author{
Alice Chan, Gerda Tawfik, and Wilson Cheng
}

\section{INTRODUCTION}

$\mathrm{C}$ loxacillin sodium is a ß-lactam antibiotic commonly used to treat gram-positive infections, especially those caused by Staphylococcus aureus. Cloxacillin may be administered as an infusion prepared in $0.9 \%$ sodium chloride (normal saline [NS]), 5\% dextrose in water, or lactated Ringer's solution. Along with cloxacillin, patients may be receiving other drugs by simultaneous or sequential Y-site administration, including other glycopeptide antibiotics such as vancomycin hydrochloride. In clinical practice, cloxacillin and vancomycin have been initiated concurrently as empiric therapy while awaiting the results of organism identification and sensitivity testing. As well, in vitro synergy with the combination of glycopeptides and B-lactams has been described in clinical isolates of vancomycin-susceptible, methicillin-resistant $S$. aureus, heterogeneous glycopeptide intermediate resistant $S$. aureus, and glycopeptide-intermediate $S$. aureus. ${ }^{1-3}$ No compatibility information for administering cloxacillin simultaneously or sequentially with vancomycin has been published. ${ }^{4}$

This study was initiated after a nurse at the authors' institution reported formation of a gel-like substance in the polyvinyl chloride (PVC) IV volume-control set and line. The observation was made during administration of cloxacillin and vancomycin sequentially through a Y-site connector (separated by NS flush). The drugs were being given for empiric treatment of infective endocarditis while awaiting results of sensitivity testing of $S$. aureus. The purpose of this study was to determine the physical compatibility of cloxacillin diluted for infusion with vancomycin during simulated Y-site administration, as assessed by visual observation.

\section{METHODS}

Cloxacillin sodium for injection was supplied in sterile 2-g vials (SteriMax, Mississauga, Ontario). For this study, the drug was reconstituted and diluted to a concentration of $25 \mathrm{mg} / \mathrm{mL}$ in NS (Baxter, Mississauga, Ontario). Vancomycin hydrochloride, supplied in 10-g sterile vials (Pharmaceutical Partners of Canada, Richmond Hill, Ontario), was reconstituted and diluted to a concentration of $10 \mathrm{mg} / \mathrm{mL}$ in NS. These are the representative concentrations recommended by the institution's parenteral drug manual for administration to patients.

Y-site administration was simulated by mixing various volumes of cloxacillin sodium with various volumes of vancomycin hydrochloride (with or without addition of NS to give a final total volume of $2 \mathrm{~mL}$ ) in PVC test tubes to test compatibility across a range of concentrations for each drug. Each combination was prepared in triplicate. All manipulations were carried out on a countertop at room temperature.

All solutions were examined with the unaided eye under normal fluorescent light by one observer (W.C.). Inspections were performed immediately after mixing and again at $1 \mathrm{~h}$ after mixing. The mixtures were stored at room temperature (approximately $25^{\circ} \mathrm{C}$ ) under constant fluorescent light.

Control solutions were cloxacillin in NS for injection, vancomycin in NS, and NS alone. Incompatibility was defined as any visible particulate matter, substantial haze or change in turbidity relative to the controls, change in colour, or evolution of gas.

\section{RESULTS}

Various concentrations of each drug were tested, from 0.8 to $23.75 \mathrm{mg} / \mathrm{mL}$ for cloxacillin and from 0.3 to $9.5 \mathrm{mg} / \mathrm{mL}$ for vancomycin. Incompatibility was recorded if formation of a white gel-like matter was observed, either immediately or $1 \mathrm{~h}$ after mixing (Table 1). In cases where incompatibility occurred at time 0 , development of the matter was dramatic, and the precipitate did not dissipate with shaking and storage at room temperature for $1 \mathrm{~h}$. Immediate development of the white gel-like matter was observed when the concentration of vancomycin reached $2 \mathrm{mg} / \mathrm{mL}$ and that of cloxacillin reached $12.5 \mathrm{mg} / \mathrm{mL}$. Delayed development of the gel was observed when the concentration of vancomycin was $2.5 \mathrm{mg} / \mathrm{mL}$ and 
Table 1. Observation of White Gel-Like Matter with Various Concentrations of Vancomycin and Cloxacillin in Simulated Y-site Administration

\begin{tabular}{|c|c|c|c|c|c|c|c|c|c|c|}
\hline \multirow{2}{*}{\multicolumn{3}{|c|}{ Volume of Constituents $(\mathrm{mL})$}} & \multirow{2}{*}{\multicolumn{2}{|c|}{ Final Concentration $(\mathrm{mg} / \mathrm{mL})$}} & \multicolumn{6}{|c|}{ Observation of Precipitate* } \\
\hline & & & & & \multicolumn{3}{|c|}{0 minutes } & \multicolumn{3}{|c|}{1 hour } \\
\hline $\begin{array}{l}\text { Vancomycin } \\
10 \mathrm{mg} / \mathrm{mL}\end{array}$ & $\begin{array}{l}\text { Cloxacillin } \\
25 \mathrm{mg} / \mathrm{mL}\end{array}$ & NS & Vancomycin & Cloxacillin & A & B & C & A & B & C \\
\hline 0 & 0 & 2 & 0 & 0 & No & No & No & No & No & No \\
\hline 0 & 0.10 & 1.90 & 0 & 1.25 & No & No & No & No & No & No \\
\hline 0 & 2 & 0 & 0 & 25 & No & No & No & No & No & No \\
\hline 0.06 & 0.06 & 1.88 & 0.30 & 0.80 & No & No & No & No & No & No \\
\hline 0.06 & 0.10 & 1.84 & 0.30 & 1.25 & No & No & No & No & No & No \\
\hline 0.10 & 1.90 & 0 & 0.50 & 23.75 & No & No & No & No & No & No \\
\hline 0.12 & 0.10 & 1.78 & 0.60 & 1.25 & No & No & No & No & No & No \\
\hline 0.12 & 0.14 & 1.74 & 0.60 & 1.75 & No & No & No & No & No & No \\
\hline 0.26 & 0.10 & 1.64 & 1.30 & 1.25 & No & No & No & No & No & No \\
\hline 0.26 & 0.27 & 1.47 & 1.30 & 3.40 & No & No & No & No & No & No \\
\hline 2 & 0 & 0 & 10 & 0 & No & No & No & No & No & No \\
\hline 0.40 & 0 & 1.60 & 2 & 0 & No & No & No & No & No & No \\
\hline 0.40 & 0.06 & 1.54 & 2 & 0.80 & No & No & No & No & No & No \\
\hline 0.40 & 0.14 & 1.46 & 2 & 1.75 & No & No & No & No & No & No \\
\hline 0.40 & 0.27 & 1.33 & 2 & 3.40 & No & No & No & No & No & No \\
\hline 0.40 & 0.54 & 1.06 & 2 & 6.80 & No & No & No & No & No & No \\
\hline 0.40 & 1 & 0.60 & 2 & 12.50 & Yes & Yes & Yes & Yes & Yes & Yes \\
\hline 0.40 & 1.60 & 0 & 2 & 20 & Yes & Yes & Yes & Yes & Yes & Yes \\
\hline 0.50 & 0.10 & 1.40 & 2.50 & 1.25 & No & No & No & Yes & Yes & Yes \\
\hline 0.50 & 0.54 & 0.96 & 2.50 & 6.80 & Yes & Yes & Yes & Yes & Yes & Yes \\
\hline 1 & 0.10 & 0.90 & 5 & 1.25 & Yes & Yes & Yes & Yes & Yes & Yes \\
\hline 1 & 1 & 0 & 5 & 12.5 & Yes & Yes & Yes & Yes & Yes & Yes \\
\hline 1.60 & 0.40 & 0 & 8 & 5 & Yes & Yes & Yes & Yes & Yes & Yes \\
\hline 1.90 & 0.10 & 0 & 9.50 & 1.25 & Yes & Yes & Yes & Yes & Yes & Yes \\
\hline
\end{tabular}

NS $=$ normal saline $(0.9 \%$ sodium chloride).

* $A, B$, and $C$ represent the 3 replicates. "Yes" indicates that particulate matter was observed. "No" indicates that no precipitate matter was observed.

that of cloxacillin was $1.25 \mathrm{mg} / \mathrm{mL}$. These concentrations are substantially lower than the standard concentrations commonly used at the authors' institution (vancomycin $10 \mathrm{mg} / \mathrm{mL}$ and cloxacillin $25 \mathrm{mg} / \mathrm{mL}$ ). Thus, it is likely that this incompatibility will occur when these medications are administered at the usual concentrations recommended in the literature.

\section{DISCUSSION}

In experiments simulating simultaneous Y-site administration of vancomycin and cloxacillin, formation of a white gel-like matter clearly indicated physical incompatibility between these 2 drugs. We are unsure why this incompatibility has not previously been described in the literature, given the dramatic and immediate way in which the gel-like matter formed. We hypothesize that concurrent or sequential administration of these 2 antimicrobials may be uncommon in clinical practice because of overlap of most of the spectra of activity of these 2 agents. Alternatively, in instances where there is an indication for both agents, patients may have multiple sites for IV access, so separate sites of administration may be used.
Notably, precipitation also occurred in instances when the concentration of one drug was much lower than its standard concentration and the concentration of the second drug remained near its standard concentration; as such, physical incompatibility may occur if residual drug remains in the patient's IV administration set after administration of one antimicrobial followed by infusion of the second drug through the same administration set. We postulate that this was the situation in the incident that prompted this study. In that case, a gel-like substance appeared in the IV volume-control set and line during administration of vancomycin immediately following administration of a dose of cloxacillin with NS flush between. Since it is common practice in sequential administration of parenteral drugs to flush the administration set with a fluid bolus between medications (to avoid incompatibilities), it is important to note that this procedure will likely not prevent the interaction between cloxacillin and vancomycin.

This study was hypothesis-generating with regard to duration of exposure as a contributor to the formation of precipitate and whether prolonged contact increases the likelihood of incompatibility. However, delayed formation of 
precipitate occurred with only one combination of concentrations (vancomycin $2.5 \mathrm{mg} / \mathrm{mL}$ and cloxacillin $1.25 \mathrm{mg} / \mathrm{mL}$ ), and the exact time at which the precipitate formed was uncertain. This temporal or duration-of-contact relation should be verified with further experiments examining duration of contact of the medications with respect to different concentrations of each agent. Regardless, this incompatibility poses a risk in clinical practice when medication IV administration sets are primed with both medications and there is a delay in running them or when the drugs are run through administration sets that are not changed frequently. There may even be a risk with normal repeated exposure of administration sets to the medications running through them with changes at appropriate frequencies.

\section{CONCLUSIONS}

Physical incompatibility of cloxacillin and vancomycin, visible to the unaided eye, was dramatic and immediate at certain concentrations. The incompatibility occurred at concentrations of vancomycin $2 \mathrm{mg} / \mathrm{mL}$ and cloxacillin $1.25 \mathrm{mg} / \mathrm{mL}$ and above, a range that includes many of the concentrations recommended for administration of these 2 drugs. Cloxacillin and vancomycin are not compatible for concurrent Y-site administration and are likely incompatible for sequential administration separated by a fluid bolus flush through lines and administration sets.

\section{References}

1. Domenech A, Ribes S, Cabellos C, Taberner F, Tubau F, Dominguez MA, et al. Experimental study on the efficacy of combinations of glycopeptides and beta-lactams against Staphylococcus aureus with reduced susceptibility to glycopeptides. J Antimicrob Chemother. 2005;56(4):709-16.
2. Leonard SN. Synergy between vancomycin and nafcillin against Staphylococcus aureus in an in vitro pharmacokinetic/pharmacodynamic model. PLoS One. 2012;7(7):e42103.

3. Szymanska G, Szemraj M, Szewczyk EM. Species-specific sensitivity of coagulase-negative staphylococci to single antibiotics and their combinations. Pol J Microbiol. 2011;60(2):155-61.

4. Trissel LA. Handbook on injectable drugs. 16th ed. Bethesda (MD): American Society of Health-System Pharmacists; 2011.

Alice Chan, BSc(Pharm), ACPR, PharmD, is Clinical Practice Leader, Alberta Health Services, Edmonton, Alberta.

Gerda Tawfik, BSc(Pharm), is a Staff Pharmacist in the Department of Pharmacy at Stollery Children's Hospital/University of Alberta Hospital, Edmonton, Alberta.

Wilson Cheng, $\mathrm{BSC}(\mathrm{Pharm}), \mathrm{PhD}$, is Acting Manager of the Pharmacy Department, University of Alberta Hospital/Stollery Children's Hospital/Mazankowski Alberta Heart Institute, Edmonton, Alberta.

Competing interests: None declared.

Address correspondence to:

Dr Alice Chan

Alberta Health Services

OG1.01 WMC

8440112 Street

Edmonton AB T6G 2B7

e-mail: Alice.W.Chan@albertahealthservices.ca

\section{Acknowledgement}

The authors would like to thank Andrea Hiebert, a nurse in the pediatric intensive care unit of the Stollery Children's Hospital for her contribution to this manuscript. 